\title{
Os Estudos de Economia Doméstica na Formação da Mulher Rural
}

\author{
NEWTON BELEZA \\ Superintendente do Ensino Agrícola e Veterinário
}

\begin{abstract}
A
SSUMe para nós interêsse particular a difusão que se fizer sôbre estudos de economia doméstica para que chegue a todos o conhecimento de seus objetivos, até criar-se o senso — que ainda nos falta — da responsabilidade pública e coletiva nesse campo de realizações.
\end{abstract}

Surgirá disso um balanço da nossa situação, evidenciando-se não sòmente o que ainda não se fêz — que é quase tudo - como o que já se tem feito que é muito pouco em relação aos genuínos reclamos de nosso desenvolvimento social - mas, ainda assim, está desconhecido de quase tôda a gente.

Costuma-se, com certa razão, acusar o povo brasileiro de não ter iniciativa para os empreendimentos sociais ou dêles alhear-se, contando sempre com a mediação do govêrno para operar o milagre da solução de seus problemas. Não seria talvez difícil verificar-se também que a própria administração pública tolhe a iniciativa particular, arvorando-se em detentora de todos os poderes sem auscultar a opinião pública.

Deixando de lado êsse aspecto psicológico de nossa formação, com fundamento em nossas origens, é curioso observar-se que, no caso dos estudos de economia doméstica, tem a iniciativa particular precedido a ação pública.

Até bem pouco tempo, em verdade, nas estruturações do ensino entre nós, não se cogitara dos estudos de economia doméstica como cursos autônamos regulares. Data de pouco a consagração em lei dos estudos de economia doméstica, em nível correspondente ao colegial, não portanto ainda de grau superior, como seria de desejar.

Antes, porém que a União instalasse escolas de economia doméstica ou incluisse em lei essa modalidade de ensino, em vários pontos do país foi sendo tentada, por iniciativa particular, a manutenção de cursos dessa natureza. E coube a uma das menores e mais modestas unidades da Federação - o Estado do Rio Grande do Norte - como pioneiro, assegurar a existência de um estabelecimento condigno na especialidade, abrindo novos rumos ao sistema educacional brasileiro. Há mais de 40 anos existe, de fato, uma Escola de Economia Doméstica em Natal, justamente afamada em todo o país, e conhecida de todos nós. 
Através do Ministério da Agricultura, em 1946, com o Decreto-lei número 9.613 e com o Decreto n. $^{\circ}$ 21.667, pela primeira vez, foram estabelecidos e regulamentados os cursos de Magistério de Economia Rural Doméstica, destinados sobretudo à educação para as atividades tìpicamente femininas no âmbito da vida dos campos, ao mesmo tempo em que era assegurada à mulher igualdade de direito quanto a ingresso em todos os cursos para formação agrícola.

Antes disso, com a regulamentação do ensino agrícola que baixou com - Decreto n. ${ }^{\circ} 8.319$, de 20 de outubro de 1910 , vagamente foram previstas, mas nunca postas em execução, umas escolas domésticas agrícolas, de caráter elementaríssimo, ligadas aos estudos primários, visando a preparar as filhas dos cultivadores para os misteres da vida aǵrícola, conforme a expressão contida na própria lei.

Sòmente depois da vigência do Decreto-lei n. ${ }^{\circ} 9.613$, de 20 de agôsto de 1946, que codificou a chamada Lei Orgânica do Ensino Agrícola, é que começou a existência oficial dos cursos de economia rural doméstica. cuja execução foi iniciada como parte do programa a que se propunha a Comissão Brasileiro-Americana de Educação das Populações Rurais, mantida então em regime de acôrdo entre os Governos Brasileiro e Norte-Americano.

Havendo o Govêrno Norte-Americano perdido o interêsse na manutenção dêsse acôrdo - de sorte muito diversa de outro - idêntico lavrado na mesma época para o ensino industrial; que até hoje subsiste com excelentes resultados - passaram os cursos de economia rural doméstica a ser mantidos com recursos não sòmente da Comissão Brasileira de Assistência Educativa das Populações Rurais, em que se transformou a Comissão Brasileiro-Americana, como de dotações específicas consignadas na Verba 3 do Orçamento da União para serviços educativos e culturais.

Como um dos principais colaboradores e, portanto, intérpretes da Lei Orgânica do Ensino Agrícola devo prestar o meu depoimento de que a soluçäo adotada, com fundamento em recursos orçamentários de natureza instável, prejudicou o desenvolvimento e a consolidação do ensino da economia rural doméstica, que até hoje não tem a organização definitiva que se prevê no atơ de sua criação.

De conformidade com a lei, a sua manutenção devia fazer-se ou pela criação, em caráter permanente, de escolas de economia rural doméstica isoladas, ou de cursos dessa especialidade em conexão com as escolas de agricultura já existentes, ou a serem fundadas, para rapazes, correndo as respectivas despesas, em qualquer das duas hipóteses, por conta das mesmas dotações orçamentárias que servem à rêde federal de estabelecimentos de ensino agrícola.

Ficou também prejudicado o que dispõem sàbiamente os artigos $51 \mathrm{e}$ 52 e seus incisos, da Lei Orgânica do Ensino Agrícola no Título V - Do ensino agrícola feminino - pelos quais foi assegurado às mulheres o direito já conferido aos homens de ingresso em todos os cursos de ensino agrícola, ao mesmo tempo em que é traçada uma orientação para os casos especiais de preparação feminina. 
Não obstante os têrmos claros da Lei, como antes de sua existência, não vinham sendo até agora franqueadas às mulheres as matrículas nos cursos de iniciação agrícola, de mestria agrícola e agrotécnicos, nem sequer havia sido destinada à preparação feminina nenhuma escola dêsse tipo embora houvesse sido prevista ou a coeducação quando aconselhável, ou escolas especialmente para mulheres.

Numerosos foram, entretanto, os novos estabelecimentos surgidos nestes últimos tempos, sobretudo em regime de acôrdo com os Estados, orientados sempre para a educação de homens, sobrepondo-se por consequiência a rotina aos dispositivos da lei, cujos fundamentos repousam quase sempre, como no caso dos estudos de economia doméstica, em tendências, aspirações e interêsses sociais.

Sòmente agora estão sendo tomadas as primeiras providências para a execução dêsse aspecto da Lei, que encarou acertadamente a educação como um todo que se propõe atingir, em sua atuação modificadora, homens e mutheres sem distinção e em tôdas as idades, estejam dentro do recinto das escolas ou vivam dispersos na comunidade, absorvidos nos seus afazeres cotidianos.

Pouco significaria, de fato, a existência de cursos de economia rural doméstica se fôssem concebidos para viver isoladamente, e não como partes integrantes de um sistema educacional que ofereça articulação para cima e para baixo e para todos os lados, em ciclos que se superpõem e se juxtapõem num perfeito regime de vazos comunicantes.

Nem seria obra de justiça, de simples justiça, que se mantivessem cursos de formação agrícola, correspondentes aos níveis ginasial e colegial, só para homens, com exclusão de mulheres, desclassificando-se por si mesmo um diploma legal que traisše no seu texto a ignorância dos direitos e conveniências sociais, que só pode ser perdoável aos indivíduos.

O simples exame do papel desempenhado pela mulher no conjunto social demonstra ser absolutamente indispensável a sua colaboração consciente em qualquer empreendimento. O seu raio de influência é maior do que o do homem, cujaș mudificações para melhor quase sempre se restringem aos seus próprios atos, enquanto a mulher, pela sua própria natureza messiânica as transmite a todos aqueles com quem convive.

De outro lado, incumbe à mulher a administração do lar, que constitui uma unidade econômica de que depende a vida social, para o seu equilíbrio e aperfeiçoamento. Se todos os lares, ou a sua maioria forem bem administrados, se progredirem na adoção de métodos racionais de viver, receberá o conjunto social o reflexo e os benefícios dessa situação.

Não será possível, portanto, pensar-se em melhoramento dos processos utilizados na agricultura, em desenvolvimento dơ meio rural, em aperfeiçoamento dos padrões de vida nos campos sem a adesão consciente da mulher preparada em igualdade de condições com aqueles em cuja companhia irá viver, como espôsa companheira, professôra, mãe ou irmã.

Reconheça-se também, em benefício do interêsse públicơ a que todos nos devotamos, que a Lei Orgânica do Ensino Agrícola, com as belas transforma- 
ções de ordem educativa que nos trouxe, ainda contém as suas falhas, havendo mesmo deixado obscuros alguns pontos relacionados com os estudos de economia doméstica. Acha-se a Superintendência do Ensino Agrícola e Veterinário empenhada no momento, em fazer-lhes as correções necessárias.

Ficaremos na dependência de um ato do Legislativo para que se corrijam algumas dessas falhas, $\sigma$ que implica, evidentemente, num transcurso de tempo bem longo, pois que um projeto de Lei, habitualmente, não transita nas duas casas do Congresso dentro de uma legislatura. Não são, todavia, de inadiável importância os pontos a serem corrigidos em Lei. Entre êles inclui-se, todavia, a necessidade, conquanto não premente, de se prever o ensino de economia doméstica no quadro do ensino superior do país.

A premência maior de alteração, no que diz respeito particularmente à economia rural doméstica, prende-se aos seus currículos que foram baixados pelo Decretơ n. ${ }^{\circ}$ 21.667. de 20 de agôsto de 1946, e que, à luz da experiência, não se têm revelado satisfatórios. Em verdade, se tivesse havido tempo para estudo mais acurado, poderiam êles ter sido considerados insuficientes, mesmo à data de sua aceitação.

Como resultado dos estudos, das observações e das experiências colhidas posteriormente pela Superintendência do Ensino Agrícola e Veterinário, no interregno de cêrca de oito anos decorridos da data da assinatura do referido decreto, já foram elaborados outros para o curso de magistério de economia rural doméstica, que melhor correspondem à conveniência do ensino dessa especialidade.

Compõem-se os novos currículos das seguintes disciplinas:

\section{Cultura Geral}

Português

Matemática

Ciências Físicas e Naturais

Cultura Técnica

Atividades Agrícolas

Desenho Aplicado

Dietética e Arte Culinária

Noções de Puericultura

Indústrias Rurais Caseiras

Confecção de Adôrnos e Utensílios Domésticos

Corte e Costura

Higiene e Enfermagem

Nơ̧ões de Psicologia Educacional e Sociologia Rural

Metodologia

Administração Escolar

Administração e Arranjo do Lar -Rural

Práticas Educativas

Recreação e Jogos Educativos

Canto Orfeônico 
Como parte de um trabalho de revisão procedida em todos os currículos referentes aos cursos de que trata a Lei Orgânica do Ensino Agrícola, foi o novo currículo de economia doméstica incluído num projeto de decreto para a aprovação do novo Regulamento dos Currículos do Ensino Agrícola, recentemente encaminhado ao Senhor Presidente da República, com plena aprovação e aplausos do Ministro Munhoz da Rocha, atual detentor da pasta da Agricultura. Oportunamente, será encaminhado o expediente necessário para as modificações aconselháveis na própria Lei, conforme autorização de Sua Excelência.

E' motivơ de satisfação especial anunciar estas novas, no momento em que se promove, no recinto da Universidade Rural do km. 47, uma conferência de Economia Doméstica, porventura a primeira no gênero, que indica o quanto vem tomando vulto o interêsse pela implantação definitiva entre nós dos estudos dessa especialidade.

Deve-se a iniciativa principalmente aos esforços de especialistas que trabalham no Escritório Técnico de Agricultura, mantido mediante um acôrdo entre os Governos Brasileiro e Norte-Americano, entre os quais se encontra Miss Dorothy Elizabeth Williams que se tem devotado à expansão e ao aperfeiçoamento dos estudos de economia doméstica no Brasil.

Ficará a aplicação dos novos currículos condicionada a princípios educacionais genéricos, que asseguram a sua maior eficiência e já incorporados à Lei Orgânica do Ensino Agrícola, como sejam:

- Fundamento nas atividades sociais em que repousa o convívio e a interação de todos os seres humanos.

- Sentido cultural à sua organização para que se integre no sistema geral de educaçãa.

- Conjugação de cursos regulares com a educação extensiva para que se beneficiem de um constante melhoramento para a vida os que se acham fora da chamada idade escolar.

- Igualdade de direito a homens e mulheres para a garantia de harmonização no desenvolvimento do conjunto social.

\section{SUMÁRIO}

Ao ensejo da reunião da $1^{\text {a }}$ Conferência de Economia Doméstica, realizada na Universidade Rural do $\mathrm{km} 47$ de 11 a 16 de julho dêste ano, faz o autor um balanço do que tem ocorrido em nosso pais para estudos da especialidade, concluindo que data de muito pouco tempo o reconhecimento oficial de cursos dessa natureza.

De modo geral, antecipou-se a iniciativa particular sôbre as providências emanađas dos poderes públicos, registrando-se além de várias outras tentativas na esfera particular, a existência de há mais de 40 anos, de uma Escola de Economia Doméstica em Natal, no Rio Grande do Norte, justamente afamada e conhecida em todos os recantos do país.

Entretanto, foi sòmente após a vigência do Decreto-lei n..$^{\circ} 9.613$, de 20-8-46, que codificou a chamada Lei Orgânica do Ensino Agrícola, que começou a existência oficial de cursos de economia doméstica aplicada à agricultura.

Aponta, todavia, o autor as falhas verificadas na aplicação da referida Lei, o que tem contribuído para um atraso maior na implantação entre nós de cursos condignos de ecenomia doméstica. 
Entre as falhas, salienta a maneira precária por que foi iniciado o seu funcionamento quanto a recursos financeiros, em desigualdade de condições com o tratamento dispensado às escolas profissionais agrícolas já existentes para rapazes, bem como o não reconhecimento do direito conferido às mulheres, nos artigos 51 e 52 da Lei Orgânica do Ensino Agrícola, de igualdade em relação aos homens quanto a ingresso em tôdas as escolas profissionais para a agricultura.

Acentua que seria imperfeita. uma educação para a mulher rural se ela não fôsse enquadrada no sistema geral de educação do país, articulada com os diferentes ramos de ensino, e se também à mulher não fôssem dispensadas as mesmas possibilidades gerais de que já gozam os homens.

Anuncia, do outro lado, que, depois das variadas observações e experiências colhidas com o funcionamento dos cursos de economia rural doméstica. já pôde a Superintendência do Ensino Agríccla e Veterinário concluir sôbre a necessidade de revisão dos currículos, que foram baixados logo após a Lei Orgânica do Ensino Agrícola. Dêsse modo, após os estudos necessários, foi proposta a alteração dêsses currículos dentro do novo Regulamento dos Currículos do Ensino Agrícola, recentemente encaminhado ao Ministro Munhoz da Rocha.

\section{SUMMARY}

1. The necessity of creating the sense of public responsibility as regards the field of home economics in Brazil. It is imperative to inform the people of what has been done and, particularly, of what ought to be done on the matter.

2. Home economics, not contemplated in the school curricula of the recent past, but now a subject of the second cycle of the secondary schools.

3. The "Escola Doméstica de Natal", in the State of Rio Grande do Norte, established more than forty years ago, as the pioneer school in the field of home economics.

4. The Organic Law of Agricultural Education (1946) and the beginnings of rurat courses of home economics as a part of the regular programme of the Brazilian-American Commission for the Education of Rural Populations. The functions of that Commission taken over by the Brazilian Comission for the Educational Assistance of Rural Populations.

5. Criticism of the solutions adopted by the Administration as regards the application of the Organic Law of Agricultural F.ducation. The principles concerning agricultutral education for women not fully put into practice up to quite recent times.

6. The new curricula for agricultural education. Proposed amendments to the Organic Law of Africultural. Education.

O recrutamento a cargo de um órgão central - recrutamento centralizado apresenta vantagens para a Administração, por ser amplo e ao mesmo tempo mais econômico e, por outro lado, corresponde ao interêsse dos candidatos, que mais fàcilmente se orientarão, além de, com mais eficácia, poderem exercer contrôle sôbre o órgão.

(Belmiro SiqueIRA - Política de Recrutamento - Diretrizes. R.S.P. Abril de 1950). 